EISSN: 2706-7955 ISSN: 2077-4605

DOI: $10.36632 /$ mejar/2021.10.4.87

Journal homepage: www.curresweb.com

Pages: 1291-1301

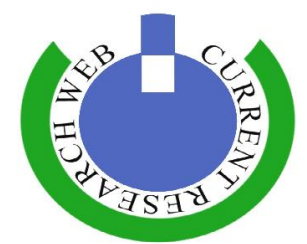

\title{
Effect of Different Designs of Drip Irrigation system on Maize Productivity in Reclaimed Lands
}

\author{
Imam H.M. ${ }^{1}$, Sabreen K. Pibars ${ }^{2}$, and Nermin S. Hussein ${ }^{1}$ \\ ${ }^{I}$ Agricultural Engineering Research Institute, Agricultural Research Center, Nadi El Seid St., Dokki, \\ Giza, Egypt. \\ ${ }^{2}$ Agricultural and Biological Research Institute, National Research Centre, El-Dokki, Cairo, Egypt.
}

Received: 20 Oct. $2021 \quad$ Accepted: 25 Nov. $2021 \quad$ Published: 05 Dec. 2021

\begin{abstract}
Drip irrigation systems consider as the most efficient of water distribution and application and an ideal way for supplying the plants with nutrients. It demonstrated a superior performance under desert conditions for sandy soils. Two field experiments were conducted in two seasons, at the experimental farm of National Research Centre (NRC), El-Nubaria, Beheira Governorate to investigate the effect of drip irrigation designs on Maize (Zea mays L., single cross 10 hybrid) production under reclaimed lands. Four different lateral designs as (double inlet, loop tube, flushing pipe, and single inlet) were tested under surface and subsurface drip irrigation systems. Results indicated that the lowest percentage of pressure drop was 6.4 and $6.6 \%$ that recorded for the double inlet design under both sub-surface and surface drip irrigation systems SSDI, SDI respectively. The highest percentage of pressure drop was 12.3 and $9.8 \%$ that recorded for the single inlet design of surface and sub-surface systems respectively. The higher emission uniformity, crop yield, and water use efficiency were recorded for the double inlet design under sub-surface drip irrigation system $96.34 \%, 11.86 \mathrm{t} / \mathrm{ha}$, and $1.699 \mathrm{~kg} \mathrm{~m}^{-3}$ comparing with single inlet design which were $90.76 \%, 9.07 \mathrm{t} / \mathrm{ha}$, and $1.344 \mathrm{~kg} \mathrm{~m}^{-3}$ under surface drip irrigation system, respectively. The statistical analysis shown a significant differences at the $5 \%$ level in both maize yield and water use efficiency between treatments. Generally, (Hydraulic performance, Emission uniformity, Crop yield, and Water use efficiency) were higher in closed designs SSDI, SDI and subsurface system comparing with single inlet design and the surface drip irrigation system.
\end{abstract}

Keywords: Maize, drip irrigation, double inlet, single inlet, and design.

\section{Introduction}

Drip irrigation has become widespread in the world due to water scarcity concerns in many parts of the world (Sahin et al., 2005). Drip irrigation system is traditionally the application of a constant steady flow of water to soil at low pressure. In this system, water is applied directly to the root zone of plants by means of applicators (drippers) operated under low pressure with the applicators being placed either on or below the surface of the ground. Water loss is minimized through these measures, as there is very little splash owing to the low pressure and short distance to the ground (Ali, 2011). Subsurface drip irrigation (SSDI) is known as one of the most effective irrigation methods capable in improving (WUE) through providing small amounts of water at short irrigation intervals and causing little or no water loss in terms of deep percolation, run-off and soil evaporation, resulting in improved water and nutrient uptake by plants and enhanced (WUE) (Nermin, 2015). Subsurface drip irrigation saves water, improves crop yields and quality, and facilitates fertilizer application; however, system performance is dependent upon skilled management (Waller and Yitayew, 2016). It is characterized by a high efficient water use due to the reduction or elimination of soil water evaporation, surface run-off, and deep percolation (Lamm and Camp, 2007).

Pressure drop occurs due to water flowing through pipes, fittings, and other components of the irrigation system. The magnitude of this energy loss depends on the velocity of the flowing water, the Corresponding Author: Imam H.M., Agricultural Engineering Research Institute, Nadi El Seid St., Dokki, Giza, Egypt. 
"roughness" of the flow path through pipes, fittings, and components, and the number of flow directional changes through fittings and components. In addition, excessive energy losses within mainlines, sub-mains, header, and/or lateral pipe sections can result in substantial variations in operating pressure and non-uniform application of water throughout the hydraulic network (Clark et al., 2007). The pressure drop in built-in lateral tubes is affected by the flow average velocity, emitter spacing, and pipe inside diameter, emitter inside diameter and emitter length (Imam et al., 2015). Distributed uniformity of water and nutrients along the laterals in traditional trickle irrigation systems are negatively affected with large reduction in pressure at the ends of laterals. Accordingly, a reduction in plant growth and yield follow the same trend (Mansour, 2016).

Better performances in terms of power consumptions, emission uniformities, savings of power and water, lower ranges in pressure regulations, pressure balancing and other associated parameters can be achieved in the multi-loop type piping systems as compared to the similar type of multilateral piping drip irrigation systems (Dhara, 2014). The mean uniformity in the proposed looped with carrier network is higher than the traditional network. The pressure distribution along the laterals in the looped with carrier network is better than that in the traditional and looped network. Clogging problems in the looped with carrier network are less than those in the traditional looped network, due to the rise in pressures at the drippers which are laid at the end of the laterals (Alabas, 2013). The closed drip network type double inlet, where the best results are in terms of uniformity of distribution and also in the lowest pressure drop, when tested using different lengths of the dripper line and also using different drippers types whether using built-in dripper or the other type is on-line dripper (Tayel et al., 2019). The double inlet and inflow-outflow system achieved better uniformity or dripper flow than that of single inlet systems used for both uniform and non-uniform slope situations. And the maximum pressure difference for the double inlet and inflow-outflow trickle irrigation systems are usually smaller than for single inlet system. The pressure difference of a double inlet or inflow-outflow lateral line system is only about one-third to one-fifth of the pressure difference caused by the single inlet system (Wu and Gitlin, 1982; Nermin, 2007; and Mohanty et al., 2016).

Maize (Zea Mays L.) s importance is considered one of the main grain crops in Egypt because of it in human, animal and poultry nutrition, as it is used in the manufacture of dry feed at rates ofit up to and in the manufacture of bread by $20 \%$. It is also used in some industries such as the extraction ,\%70 .of glucose, fructose and oil Its production in Egypt marketing year 2021/22 (Oct - Sept) at 6.4 million metric tons and the planted area at 800,000 ha (USAD, 2021).

Maize both productivity per hectare and water productivity using drip irrigation system that tended to increase the new cultivated aria. Energy savings can be also attained by using drip system to irrigate maize. Drip system can save 33\% energy used in irrigation and it can increase energy productivity from $2.81 \mathrm{~kg} / \mathrm{kW}$ under surface irrigation to $4.98 \mathrm{~kg} / \mathrm{kW}$ (Ouda et al., 2016). Hussein et al. (2018) studied the effects of full and deficit irrigation and different lateral spacing on corn yield productivity and water use efficiency in sandy soil. He found that preferable lateral spacing for corn plant was found to be $1.20 \mathrm{~m}$, which produced the maximum yield of $11.695 \mathrm{t} /$ ha with the highest water use efficiency (WUE), $1.87 \mathrm{~kg} / \mathrm{m}^{3}$.

This study targeted to select the most suitable closed drip irrigation system design to improve maize yield productivity in the reclaimed lands. The planned design should be distinguished by an efficient hydraulic performance and a better water use efficiency.

\section{Materials and Methods}

Two field experiments were conducted in two successive seasons (2018 and 2019), at the experimental farm of National Research Centre (NRC), El-Nubaria, Beheira Governorate, Egypt (30.8667 N, 30.1667 E, and main altitude 21-m above sea level). The field experiments was split block design the main plot was irrigation system (surface and sub-surface) and the sub-plots was lateral design (double inlet, loop tube, flushing pipe, and single inlet) with four replicates. The lateral tube of the subsurface irrigation system was buried at $0.2 \mathrm{~m}$ depth.

Four different types of lateral design were tested under surface and subsurface drip irrigation systems. The abbreviations of the four type's lateral designs are listed in Table (1):

Maize (Zea mays L., single cross 10 hybrid) was planted at the second week of May and growing season lasted 120 days. The soil texture was sandy, and its samples were taken every $15 \mathrm{~cm}$ from 0 to $60 \mathrm{~cm}$ the soil physical analyses are show in Table (2). 
Table 1: List of the experimental treatments and its abbreviations.

\begin{tabular}{lc}
\hline Treatments & Abbreviation \\
\hline Surface double inlet laterals & (SDI) \\
Surface loop tube laterals & (SLT) \\
Surface flushing pipe laterals & (SFP) \\
Surface single inlet laterals & (SSI) \\
Sub-surface double inlet laterals & (SSDI) \\
Sub-surface loop tube laterals & (SSLT) \\
Sub-surface flushing pipe laterals & (SSFP) \\
Sub-surface Single inlet laterals & (SSSI) \\
\hline
\end{tabular}

Table 2: Physical properties and mechanical analysis of the experimental site soil.

\begin{tabular}{ccccccccccc}
\hline \multirow{2}{*}{$\begin{array}{c}\text { Depth } \\
(\mathbf{c m})\end{array}$} & $\begin{array}{c}\mathbf{S P} \\
\mathbf{( \% )}\end{array}$ & $\begin{array}{c}\mathbf{\theta}_{\mathbf{F c}} \\
\mathbf{( \% )}\end{array}$ & $\begin{array}{c}\boldsymbol{\theta}_{\mathbf{w p}} \\
\mathbf{( \% )}\end{array}$ & $\begin{array}{c}\mathbf{A . W} \\
\mathbf{( \% )}\end{array}$ & $\begin{array}{c}\mathbf{B D} \\
\mathbf{g ~ c m}^{-3}\end{array}$ & $\begin{array}{c}\mathbf{H C} \\
\mathbf{c m ~ h r}\end{array}$ & $\begin{array}{c}\text { Course } \\
\text { sand }\end{array}$ & $\begin{array}{c}\text { Fine } \\
\text { sand }\end{array}$ & $\begin{array}{c}\text { Clay } \\
+ \text { Silt }\end{array}$ & Texture \\
\hline $0-20$ & 21 & 10.1 & 4.7 & 5.4 & 1.69 & 22.5 & 47.76 & 49.75 & 2.49 & \\
$20-40$ & 19 & 13.5 & 5.6 & 7.9 & 1.69 & 19 & 56.72 & 39.56 & 3.72 & Sandy \\
$40-60$ & 22 & 12.5 & 4.6 & 7.9 & 1.67 & 21 & 36.76 & 59.4 & 3.84 & \\
\hline
\end{tabular}

where: $\theta_{\mathrm{Fc}}=$ Field Capacity, $\theta_{\mathrm{wp}}=$ Wilting Point, $\mathrm{A} . \mathrm{W}=$ Available Water, $\mathrm{BD}=$ Bulk density $(\mathrm{g} / \mathrm{cm} 3)$, and $\mathrm{HC}$ $=$ Hydraulic conductivity $(\mathrm{cm} / \mathrm{hr})$.

The experimental area was divided into two main plots (surface and sub-surface) and every zone was divided into four sub-plots for lateral designs of $20 \times 100 \mathrm{~m}$ size. Every sub-plot was divided into four longitudinal quarters, a lateral line was selected at every quarter to determine the pressure drop profile along it, and the measuring point was selected at every 5 meters along the lateral line to measure pressure value and dripper discharge. A schematic plan of the experimental area and types of lateral design are shown in Fig. (1).

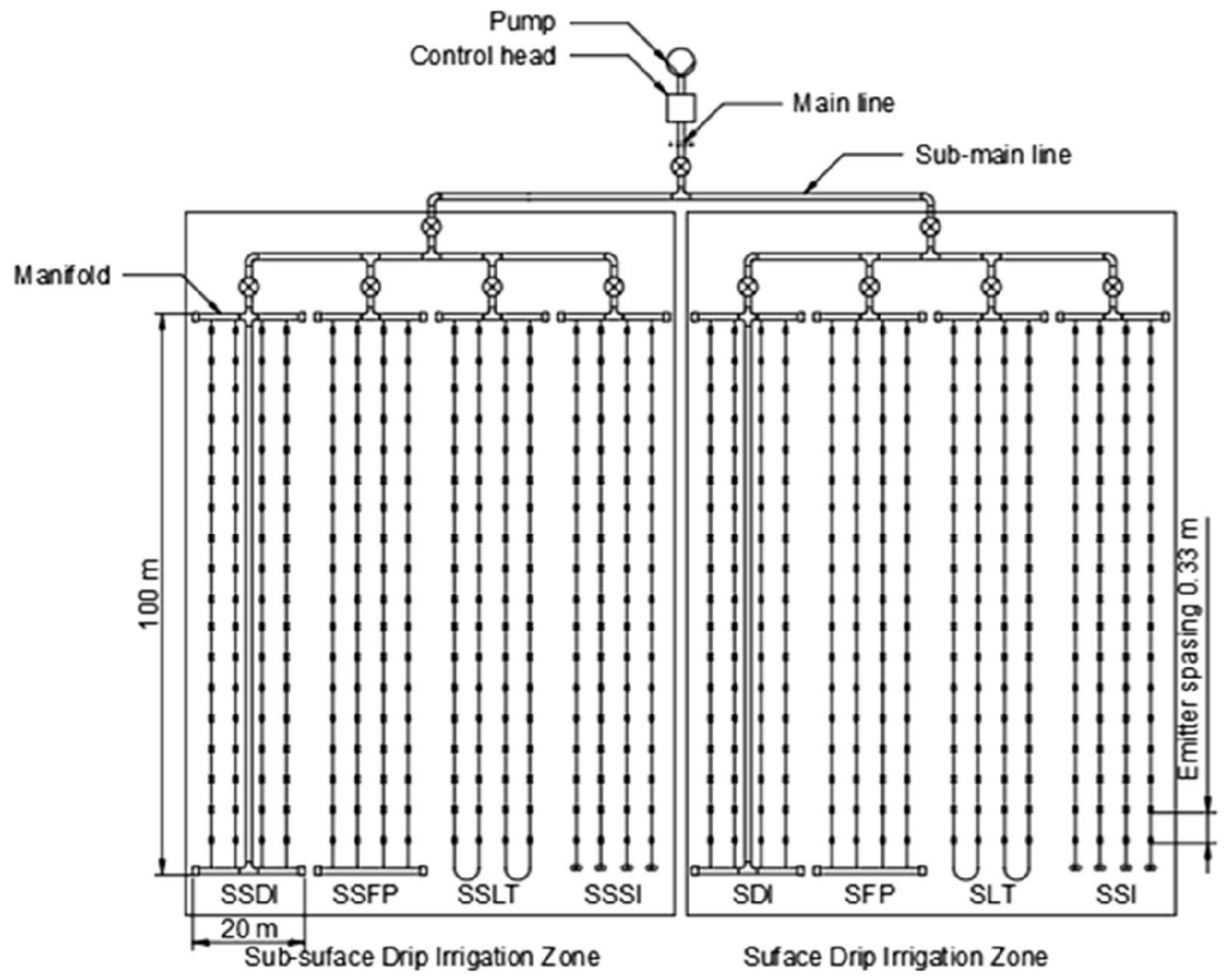

Fig. 1: Experiment design of four types of laterals connection to manifolds for surface and sub-surface drip irrigation. 
The built-in drippers were tested at the National Irrigation Devices Testing Laboratory of the Agricultural Engineering Research Institute (AEnRI), ARC under 0.5 to 1.25 bar operating pressures for four replicates to determine it's the actual hydraulic performance.

Irrigation system composed of a control head, valves, and pipeline network, that could be summarized as follows: 1) Control head: It consists of a centrifugal pump 3/3, driven by electric engine (pump discharge of $80 \mathrm{~m}^{3} / \mathrm{h}$ and $40 \mathrm{~m}$ lift), two units of media filter 48", screen filter 2" (120 mesh), back flow prevention device, pressure regulator, pressure gauges, flow-meter, control valves and chemical injection port. 2) Main line: UPVC pipes of $75 \mathrm{~mm}$ (ID) to convey the water from the water source to sub-main lines. 3) Sub-main lines: two UPVC pipes of $75 \mathrm{~mm}$ (ID) were connected to the main line through a 2" ball valve for both surface and sub-surface zones. Pressure gauges were installed at the start of sub-main lines. 4) Manifolds: every sub-main line was branched into four manifolds UPVC pipes of $50 \mathrm{~mm}$ (ID) one for every of experimental treatment sub-units. Manifolds were connected to the sub-main line through control valves 1.5". 5) Lateral lines: PE tubes of $16 \mathrm{~mm}$ in (ID) were connected to the manifolds and the laterals have built-in drippers at $0.33 \mathrm{~m}$ spacing. Laterals were buried under $0.2 \mathrm{~m}$ depth from the soil surface of the row in sub-surface drip irrigation treatment as shown in Fig. (2).

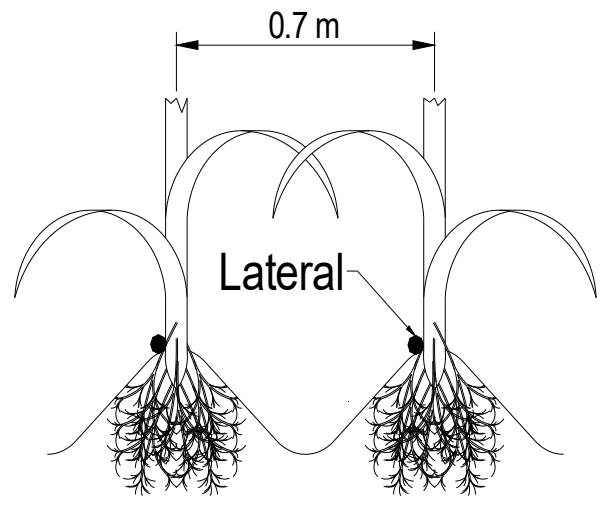

Surface laterals

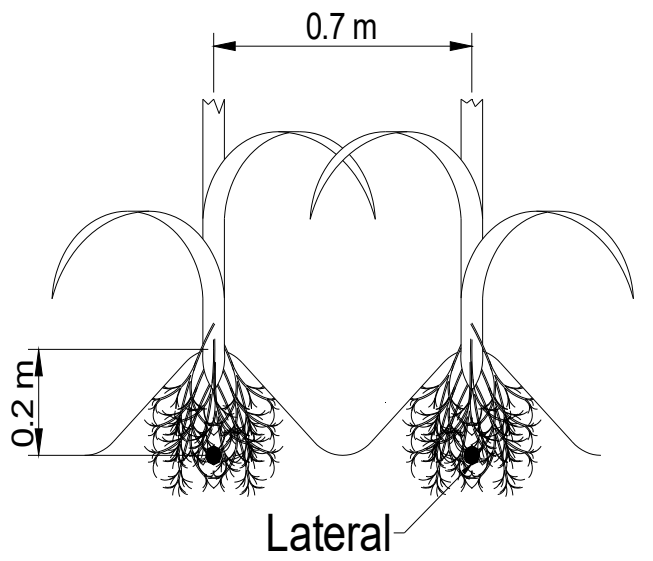

Sub-surface laterals

Fig. 2: Lateral position for surface and sub-surface drip irrigation treatments.

\subsection{Dripper Hydraulic performance}

The relationship between dripper water discharge (q) and operating pressure head (p) is found as (Clark et al., 2007):

$\mathrm{q}=\mathrm{k} \mathrm{p} \mathrm{p}^{\mathrm{x}}$

Where:

$\mathrm{q} \quad=$ Dripper discharge

$\mathrm{L} \mathrm{h}^{-1}$

$\mathrm{k}=$ Dripper discharge coefficient,

$\mathrm{x} \quad=$ Dripper discharge exponent, and

$\mathrm{p} \quad=$ Operating pressure head.

bar

\subsection{Water distribution uniformity}

Emission uniformity, EU, is a measure of the uniformity of emissions from all the emission points within an entire trickle irrigation system. For field tests calculated as follows (Killer and Bliesner, 1990):

$\mathrm{EU}=100 \mathrm{q}_{\mathrm{n}} / \mathrm{q}_{\mathrm{a}}$ 
Where:

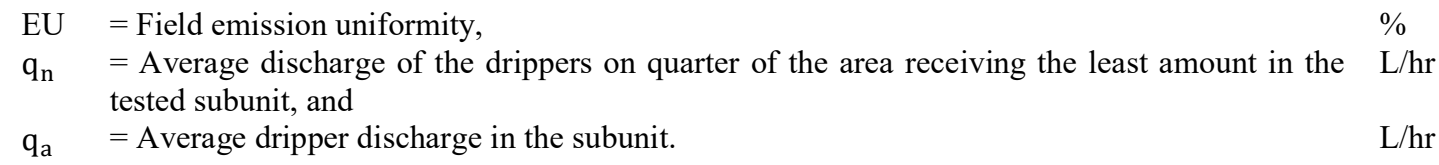

\subsection{Yield productivity}

The total yield of each treatment as determined using a frame $1 \mathrm{~m} \times 1 \mathrm{~m}$ size. The frame was placed randomly and the maize plants within the frame were weighted.

\subsection{Water use efficiency (WUE)}

This terminology refers to corn yield per cubic meter of irrigation water. It was calculated according to Israelsen and Hansen (1962) as follows:

$\mathrm{WUE}=\mathrm{Y} / \mathrm{W}$

Where:

$\begin{array}{lll}\text { WUE } & =\text { Water use efficiency, } & \mathrm{kg} \mathrm{m}^{-3} \\ \mathrm{Y} & =\text { Crop yield, and } & \mathrm{kg} \\ \mathrm{W} & =\text { Applied irrigation water. } & \mathrm{m}^{3}\end{array}$

The total yield of each treatment as determined using a frame $1 \mathrm{~m} \times 1 \mathrm{~m}$ size. The frame was placed randomly and the maize plants within the frame were weighted.

\subsection{Statistical analysis}

All data collected were statistically analyzed as a split plot design with four replications using analysis of variance to evaluate main and interaction effects as described by Snedcor and Cochran (1982). Means among treatments were compared using Least Difference (LSD) at P 0.05 probability.

\section{Results and Discussion}

\subsection{Dripper Hydraulic performance:} Table (3).

The specifications of actual hydraulic performance of the tested built-in drippers were listed in

From the presented data in Table (3) and Fig. (3), it is clear that the relationship between pressure (bar) and dripper flow rate (1/hr) class as (Clark et al., 2007). The dripper flow rate is increased by the increase of operating pressure and the dripper flow rate was $3.62391 / \mathrm{hr}$ at an operating pressure of 1 bar. The mean values of EU and $\mathrm{q}_{\mathrm{var}}$ was $93 \%$ and $19.5 \%$ which classified as acceptable values, but CV value was $6.98 \%$ which was good according to ASAE standard.

Finally, all drippers were suitable to be installed in the on-field experiments for maize production under aired region conditions.

Table 3: Hydraulic specifications of built-in dripper.

\begin{tabular}{llc}
\hline Hydraulic characteristics & & Built-in dripper \\
\hline Flow rate(l/h) & Nominal & 3.6 \\
Manufacture's coefficient of variation & Value & 6.9 \\
(CV \%) at (1 bar) & ASAE standard & Average \\
\hline \multirow{2}{*}{ Parameters } & Emitter discharge exponent (x) & 0.54 \\
& Flow coefficient $(\mathrm{k})$ & 3.62 \\
\hline Flow regime & & Turbulent flow regime \\
\hline \multirow{2}{*}{ Emission uniformity (Eu \%) } & Value & 93.2 \\
& ASAE standard & Excellent \\
\hline \multirow{2}{*}{ Emitter flow variation $(\mathbf{q} \mathbf{v a r} \%)$} & Value & 19.5 \\
& Classification & Acceptable \\
\hline
\end{tabular}




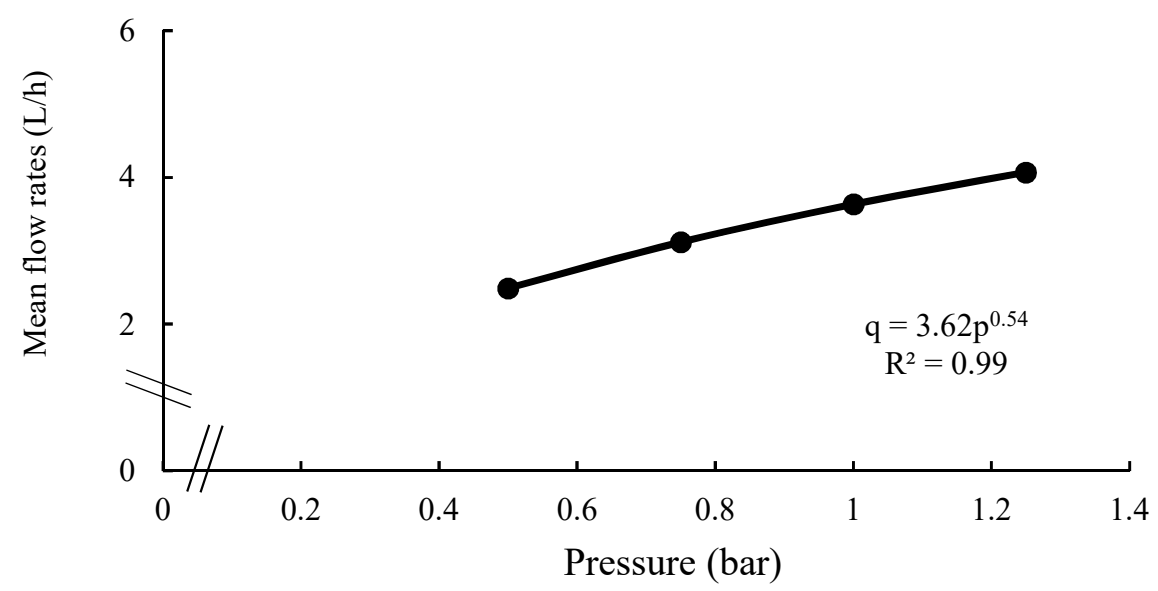

Fig. 3: The actual hydraulic performance of the built-in drippers.

\subsection{Pressure drop}

The distribution pressure drop along laterals was differed for every lateral design as presented in Fig. (4). The mean values of maximum pressure drop of the four designs are presented in table (4). The pressure drop recorded the lowest values at the beginning of laterals for every design but the distribution profile differed according to water flow through the laterals with the inlet connection to the manifold. Results indicated that the lowest pressure drop was recorded for both SSDI and SDI where the lateral connected from the both ends to feeding manifolds. The pressure drop percentages were 6.4 and $6.6 \%$ for SSDI and SDI respectively less than operating pressure of the sub-unit. The other closed surface and sub-surface systems recorded a pressure drop percentages of 9.6, 10.3, 9.2, and $8.9 \%$ less than operating pressure of the sub-unit for SLT, SFP, SSLT, and SSFP respectively. The highest pressure drop percentage was recorded to the single inlet design of both surface and sub-surface systems, and it was 12.3 and $9.8 \%$ less than operating pressure of the sub-unit for SSI and SSSI respectively.

It can be noted from the pressure drop distribution profile of both SDI and SSDI that the maximum value of pressure drop was after the middle of the laterals that was due to the flow of water from two manifolds entrance then it meets at the point after the middle of lateral. Accordingly, there was an increase in turbulent flow which increased pressure drop. The opposed water flow existed in the two other closed systems (SLT, SFP, SSLT, and SSFP) at the end of laterals as a result, the maximum values of pressure drop were recorded at the end of laterals due to water energy feedback as higher values.

Table 4: Maximum pressure drop for the four lateral designs under surface and sub-surface drip irrigation systems.

\begin{tabular}{cccccc}
\hline \multirow{2}{*}{ Design } & \multicolumn{5}{c}{ Pressure drop (bar) } \\
\cline { 2 - 6 } & L1 & L2 & L3 & L4 & Mean \\
\hline SDI & 0.056 & 0.074 & 0.068 & 0.062 & 0.065 \\
SLT & 0.093 & 0.093 & 0.096 & 0.095 & 0.094 \\
SFP & 0.102 & 0.103 & 0.101 & 0.102 & 0.102 \\
SSI & 0.110 & 0.120 & 0.123 & 0.117 & 0.117 \\
SSDI & 0.069 & 0.066 & 0.053 & 0.061 & 0.062 \\
SSLT & 0.091 & 0.089 & 0.092 & 0.092 & 0.091 \\
SSFP & 0.086 & 0.089 & 0.089 & 0.088 & 0.088 \\
SSSI & 0.089 & 0.093 & 0.098 & 0.094 & 0.093 \\
\hline
\end{tabular}




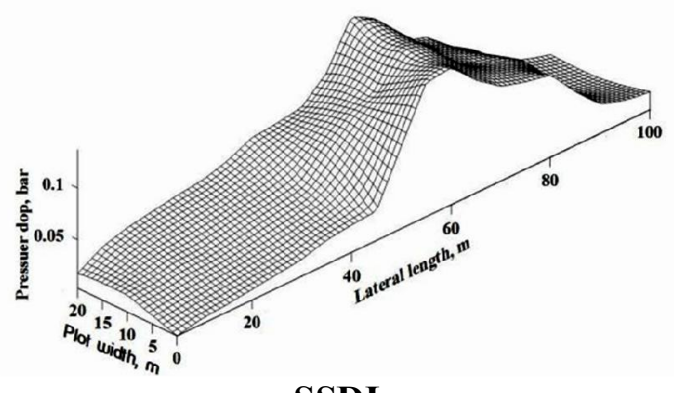

SSDI

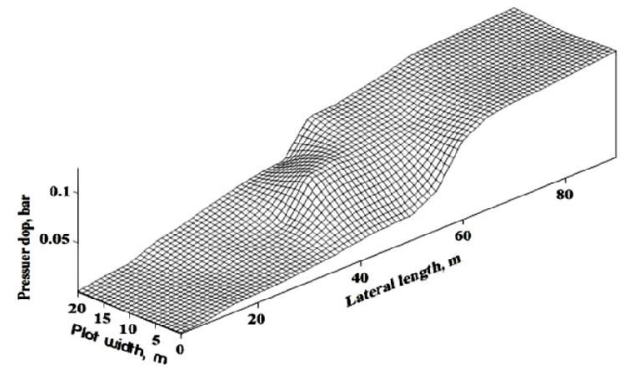

SSLT

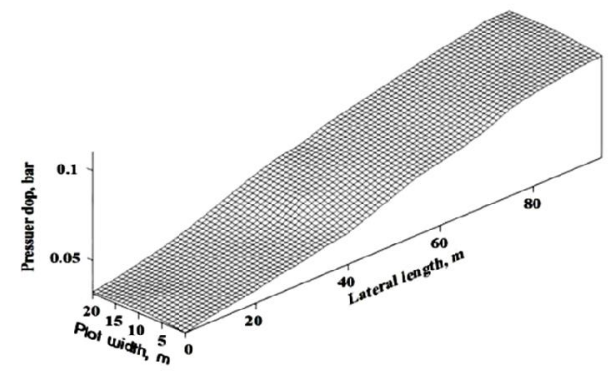

SSFP

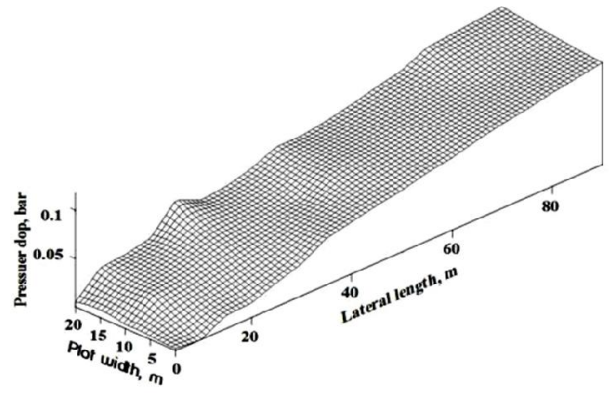

SSSI

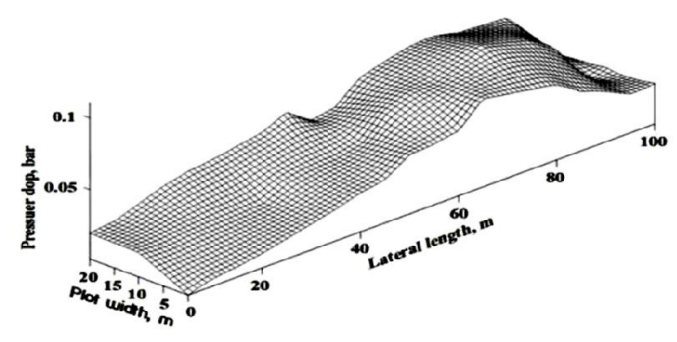

SDI

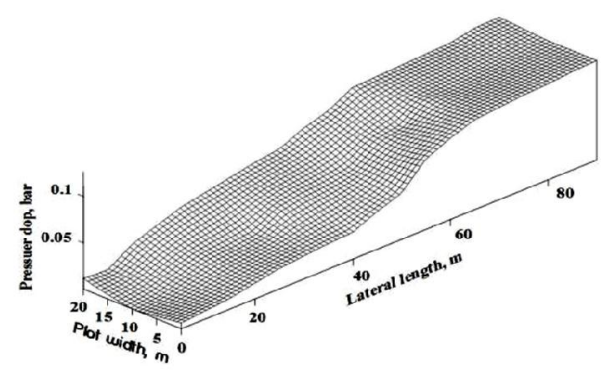

SLT

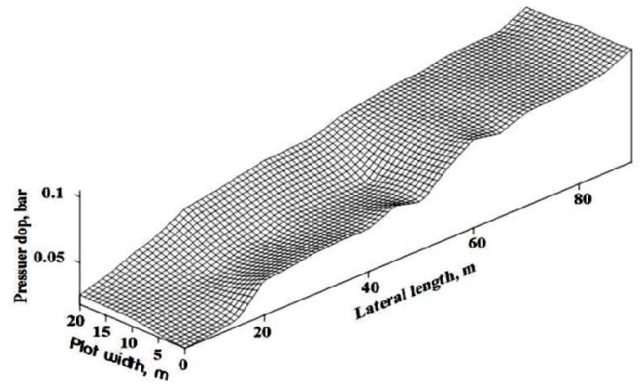

SFP

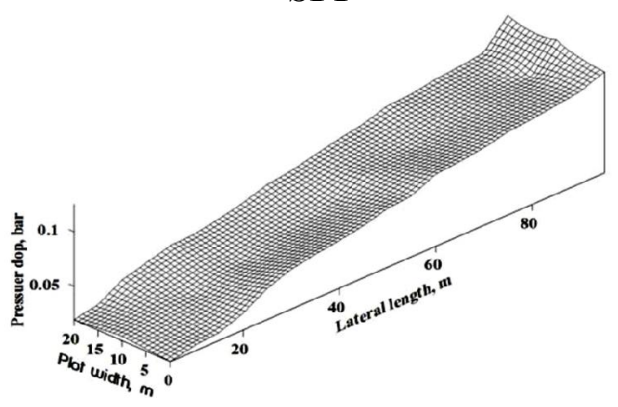

SSI

Fig. 4: Pressure distribution profile for the four types of lateral connection under surface and sub-surface drip irrigation systems.

\subsection{Emission uniformity}

The emission uniformity (EU) for every lateral design was changed with a change in pressure drop as it is shown in Fig. (5). the higher emission uniformity was observed for closed systems comparing the unclosed system. The emission uniformity values were $96.34,95.67,93.82$, and $91.62 \%$ for SSDI, SSLT, SSFP, and SSSI repetitively for sub-surface drip irrigation system and it were 95.32, $94.49,92.17$, and $90.76 \%$ for SDI, SLT, SFP, and SSI, repetitively under surface drip irrigation system.

The pressure drop variation was lower along the manifolds and also along the individual laterals in closed lateral design compared to the single inlet design. A better pressure distribution throughout 
the network was existed, which achieved higher values of emission uniformities as compared to the single inlet type configuration. These results agreed with both (Dhara, 2014; and Mohanty et al., 2016).

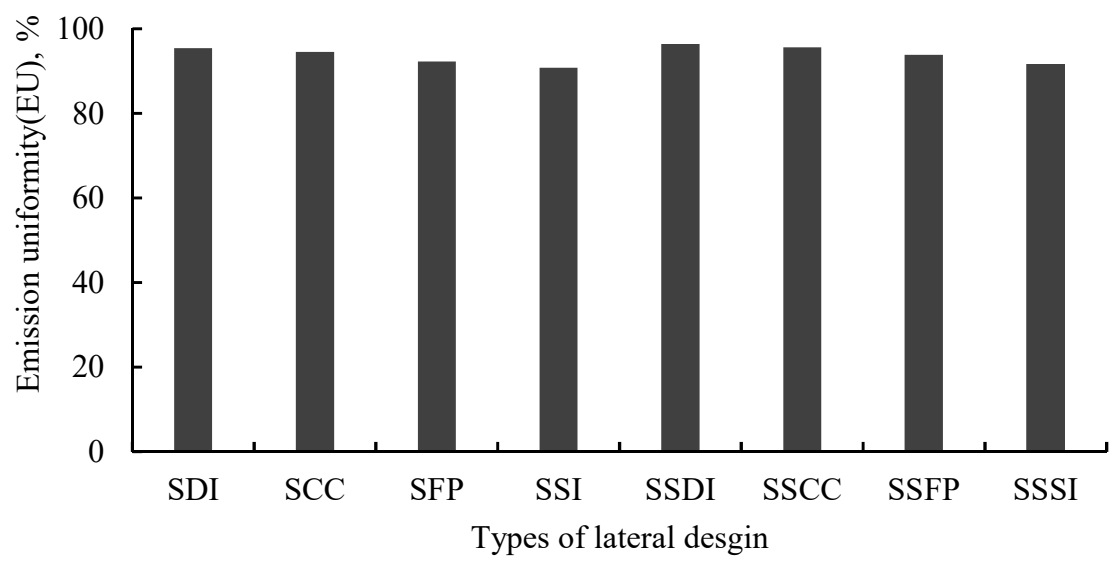

Fig. 5: Emission uniformity for the four types of lateral design under surface and sub-surface drip irrigation systems.

\subsection{Yield productivity}

The higher yield productivity was produced for the sub-surface than the surface treatments as it can be seen in Fig. (6) due to highest water use by decreasing the water evaporation from soil surface. Also, the closed irrigation systems improved the yield productivity comparing with single inlet treatments. The highest yield produced was about $11.86 \mathrm{t} /$ ha for SSDI treatment where the lowest yield was recorded about $9.07 \mathrm{t} /$ ha for SSI treatment. The other sub-surface drip irrigation treatments produced about 11.57, 10.26, and $9.67 \mathrm{t} / \mathrm{ha}$ for SSLT, SSFP, and SSSI respectively. The surface drip irrigation treatments produced about 9.57, 9.38, and $9.07 \mathrm{t} /$ ha for SLT, SFP, and SSI treatments.

The main advantage described for the sub-surface drip irrigation treatments that the less irrigation water was applied which is agree with (Wichelns, 2007). The applied irrigation water in the sub-surface drip irrigation systems would not lost by evaporation from the soil surface as it was happened in which improved maize yield productivity. A certain amount of applied irrigation water was lost by evaporation in surface drip irrigation treatments especially under the weather conditions of desert reclaimed lands. The statistical analysis showed that there were significant differences in maize yield at the $5 \%$ probability level and as of result using subsurface drip irrigation system and closed lateral designs treatments as shown in Table (4).

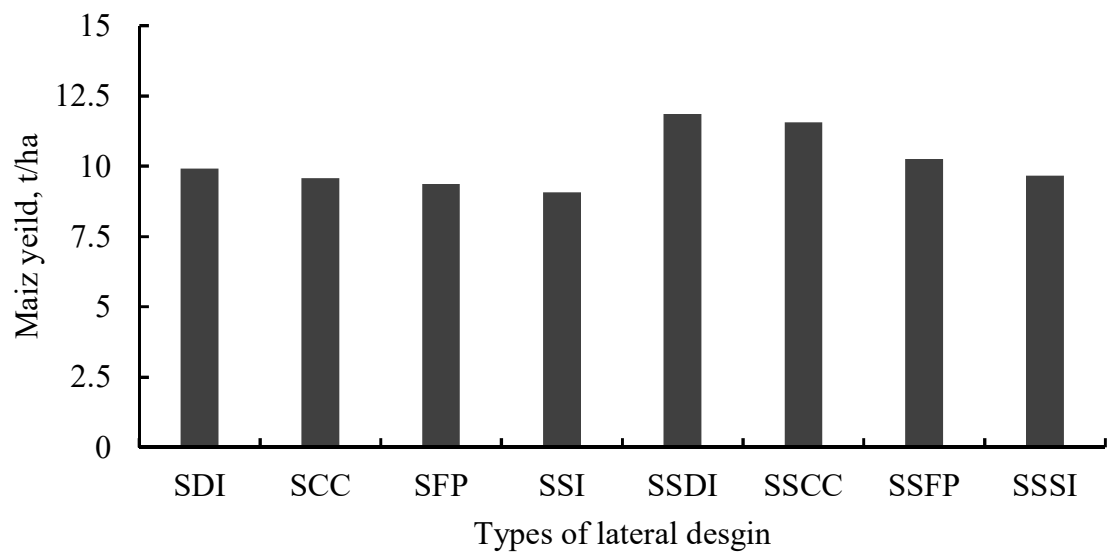

Fig. 6: Maize yield for the four types of lateral design under surface and sub-surface drip irrigation systems. 


\subsection{Water use efficiency (WUE)}

Water use efficiency (WUE) represents a given level of biomass or grain yield per unit of water used by the crop. Results shown in Fig. (7) Indicated that the highest WUE was $1.699 \mathrm{~kg} \mathrm{~m}^{-3}$ for SSDI design with an increase $30.8 \%$, while the WUE of SDI was $1.423 \mathrm{~kg} \mathrm{~m}^{-3}$ with $9.54 \%$ higher comparing SSI which was the lowest WUE $\left(1.299 \mathrm{~kg} \mathrm{~m}^{-3}\right)$. The other closed sub-surface drip irrigation designs were 1.66 , and $1.47 \mathrm{~kg} \mathrm{~m}^{-3}$ with a percentage 27.6 , and $13.24 \%$ for SSLT, and SSFP, respectively, which were higher than the closed surface drip irrigation designs of 1.372 , and $1.344 \mathrm{~kg} \mathrm{~m}^{-3}$ with a percentage 5.62 , and $3.46 \%$ for SLT, and SSI, designs ,respectively.

It is obvious that both the sub-surface drip irrigation and closed lateral designs increased the water use efficiency (WUE) compared to the surface and singe inlet systems. Applying the sub-surface drip irrigation water decreased the loss of irrigation water by evaporation, where the closed drip irrigation systems improved water conveyance efficiency which eliminated or reduced non-productive water use leading to an increase in plant transpiration and yield (Stanhill, 1986). The statistical analysis showed that there were significant differences in WUE at the $5 \%$ probability level and as of result using subsurface drip irrigation system and the closed lateral designs treatments as shown in Table (5).

Finally, results showed that SSDI was the most efficient system design through investigating either in EU, WUE, and yield in comparison with other designs which came after in all measured parameters.

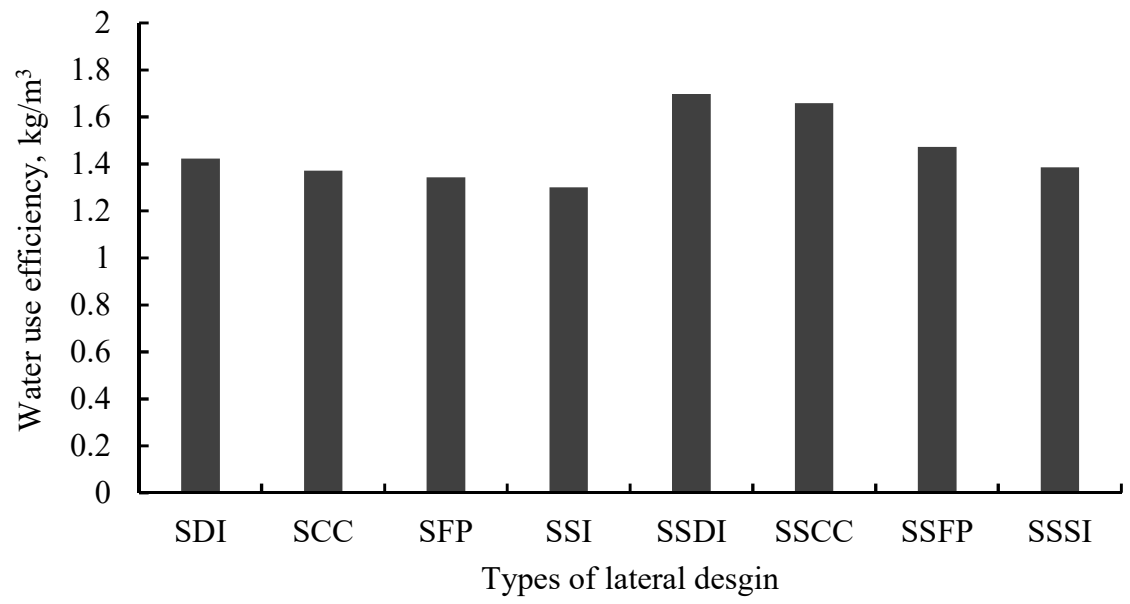

Fig. 7: Water use efficiency for the four types of lateral design under surface and sub-surface drip irrigation systems.

Table 5: Statistical analyses of emission uniformity, maize yield and WUE under drip irrigation systems and lateral designs treatments.

\begin{tabular}{cccccccc}
\hline \multicolumn{3}{c}{ Main effect of treatments } & \multicolumn{4}{c}{ Interaction between treatments } \\
Treatment & EU & Yield & WUE & Treatment & EU & Yield & WUE \\
\hline Surface & $93.185 \mathrm{~b}$ & $94.488 \mathrm{~b}$ & $1.359 \mathrm{~b}$ & SDI & $95.32 \mathrm{c}$ & $9.928 \mathrm{c}$ & $1.423 \mathrm{c}$ \\
Sub-Surface & $94.363 \mathrm{a}$ & $10.839 \mathrm{a}$ & $1.553 \mathrm{a}$ & SLT & $94.49 \mathrm{~d}$ & $9.571 \mathrm{~d}$ & $1.372 \mathrm{e}$ \\
DI & $95.83 \mathrm{a}$ & $10.714 \mathrm{a}$ & $1.561 \mathrm{a}$ & SFP & $92.17 \mathrm{f}$ & $9.381 \mathrm{e}$ & $1.344 \mathrm{f}$ \\
LT & $95.08 \mathrm{~b}$ & $10.476 \mathrm{~b}$ & $1.515 \mathrm{~b}$ & SSI & $90.76 \mathrm{~h}$ & $9.071 \mathrm{f}$ & $1.299 \mathrm{~g}$ \\
FP & $92.995 \mathrm{c}$ & $9.812 \mathrm{c}$ & $1.407 \mathrm{c}$ & SSDI & $96.34 \mathrm{a}$ & $11.857 \mathrm{a}$ & $1.699 \mathrm{a}$ \\
SI & $91.19 \mathrm{~d}$ & $9.369 \mathrm{~d}$ & $1.364 \mathrm{~d}$ & SSLT & $95.67 \mathrm{~b}$ & $11.571 \mathrm{a}$ & $1.658 \mathrm{~b}$ \\
& & & & SSFP & $93.82 \mathrm{e}$ & $10.262 \mathrm{~b}$ & $1.471 \mathrm{c}$ \\
& & & & SSSI & $91.62 \mathrm{~g}$ & $9.664 \mathrm{~d}$ & $1.385 \mathrm{~d}$ \\
\hline
\end{tabular}

Means with different letters within each column are significant at $5 \%$ level.

$\mathrm{DI}=$ Double inlet, $\mathrm{LT}=$ Loop tube, $\mathrm{FP}=$ Flushing pipe, and $\mathrm{SI}=$ Single inlet.

\section{Conclusion}

Field experiments were conducted in two seasons to investigate the effect of the closed designs for surface and sub-surface drip irrigation under maize yield. The lowest pressure drop was recorded for the double inlet design for both sub-surface and surface drip irrigation systems SSDI, SDI that 
decrease the pressure drop percentage to 6.4 and $6.6 \%$ respectively. The highest pressure drop percentage was recorded to the single inlet design of surface and sub-surface systems, SSCE, SCE and it was 12.3 and $9.8 \%$ respectively. The highest emission uniformity, crop yield, and water use efficiency were recorded for the double inlet design under sub-surface drip irrigation system $96.34 \%, 11.86 \mathrm{t} / \mathrm{ha}$, and $1.699 \mathrm{~kg} \mathrm{~m}^{-3}$ comparing with single inlet design which were $90.76 \%, 9.07 \mathrm{t} / \mathrm{ha}$, and $1.344 \mathrm{~kg} \mathrm{~m}^{-3}$ under surface drip irrigation system, respectively.

The statistical analysis shown a significant differences at the 5\% level in both maize yield and water use efficiency between treatments. Generally, Hydraulic performance, Emission uniformity, Crop yield, and Water use efficiency were higher in closed designs SSDI, SDI and sub-surface system comparing with single inlet design and the surface drip irrigation system.

\section{References}

Alabas, M.A., 2013. Evaluation the Hydraulic Performance of Drip Irrigation System with Multi Cases, Global Journal of Researches in Engineering. https://engineeringresearch.org/index.php/GJRE/article/download/836/768 .

Ali, M.H., 2011. Practices of Irrigation \& On-farm Water Management: Volume 2, Springer Science Business Media, LLC, New York, USA: 35-64.

Mohanty B., S.C. Senapati, A.P. Sahu and B. Panigrahi, 2016, Pressure Variation in Drip Laterals as Affected by Single and Double Inlet Systems and Sub Main Sizes, Journal of Agricultural Engineering Today, 40 (4): 7-12.

Clark, G.A., D.Z. Haman, and M. Yitayew, 2007, General System Design Principles. In: General system design principles, Microirrigation for Crop Production Design, Operation, and Management. Elsevier, Oxford OX5 1GB, UK: 159 - 220.

Dhara, P.K., 2014, Optimizations of Design of Different Types of Drip Irrigation Systems for Savings of Water and Energy for Various Commercial Crops, Journal of Agroecology and Natural Resource Management, 1 (1): 20-24.

Stanhill, G., 1986. Advances in Agronomy; Academic Press Inc. Published by Elsevier Inc.; (39): 5385.

Hussein, A.A., A.S.H. Mohammed and T.S. Mohammed, 2018. Effect of distance between lines of drip irrigation on corn yield in sandy soils, Egypt. J. Agric. Res., 96 (4): 1529-1541.

Imam, H.M., M.T. El-Tantawy, M.A. El-Nono and A.M. El-Gindy, 2015. Mathematical Modeling of Factors Affecting friction Head Losses on Laterals for on and Built-In Emitters; Egypt. J. Agric. Res., 93(5) (A): 227-249.

Israelsen, O.W. and V.E. Hansen, 1962. Irrigation Principles and Practices. 3rd Edition, Wiley International Edition, New York.

Keller, J. and R.D. Bliesner, 1990, Sprinkle and trickle irrigation, Springer Science Business Media, LLC, USA, 427-582.

LAMM, F.R., and C.R. CAMP, 2007. Subsurface Drip Irrigation. In: General system design principles, Microirrigation for Crop Production Design, Operation, and Management. Elsevier,Oxford OX5 1GB, UK: 473-552.

Mansour, H.A., 2016. Design Considerations for loop tube Design of Drip Irrigation System. In: loop tube Trickle Irrigation Design Theory and Applications, CRC Press, Taylor \& Francis Group, 6000 Broken Sound Parkway NW, Boca Raton, USA: 62-128.

Mohanty, B., S.C. Senapati, A.P. Sahu and B. Panigrahi, 2016. Pressure Variation in Drip laterals as affected by single and double inlet systems and sub main sizes, Agricultural Engineering Today, 40(4): 7-12.

Nermin S. Hussein, 2015. Effect of Air Addition through Subsurface Trickle Irrigation for Improving Plant-Use Efficiency in Heavy Soils, Ph.D. thesis, Faculty of Agricultural, Ain Shams University, 85-89.

Nermin S. Hussien, 2007. Evaluation of trickle irrigation designs based on uniformity concept M.SC. Ain Shams Univ.

Ouda, S., H. Farag, A. Taha, and T. Noreldin, 2016. assessment of drip irrigation system for maize to reduce food, water and energy insecurity in Egypt, Fourth African Regional Conference, Egypt, 1-13. 
Sahin, U., O. Anapal, M.F. Donmez and F. Sahin, 2005. Biological treatment of clogged emitters in a drip irrigation system. J. Environ. Manage., 76:338-341.

Snedcor, G.W. and W.G. Cochran, 1982. Statistical methods. 7th Edition, The Iowa State University Press, Iowa. [Citation Time(s):1]

Taye M.Y., Sabreen Kh. Pibars, and H.A. Mansour, 2019, The Impact of Different Closed Drip Irrigation Networks and Dripper Type on Pressure Distribution Along Lateral Lines and Uniformity, Plant Archives, 19(2): 548- 553.

(USDA) United States Department of Agriculture, 2021. Grain and Feed Annual, Egypt is able to secure a steady supply of grains during the COVID-19 pandemic https://apps.fas.usda.gov/newgainapi/api/Report/DownloadReportByFileName?fileName $=\mathrm{Gr}$ ain+and+Feed+Annual_Cairo_Egypt_03-15-2021.pdf

Waller, P., and M. Yitayew, 2016. Irrigation and Drainage Engineering, Springer International Publishing Switzerland, 289 - 304.

Wichelns, D., 2007. Economic Implications of Microirrigation. In: General system design principles, Microirrigation for Crop Production Design, Operation, and Management. Elsevier,Oxford OX5 1GB, UK, 221-258.

Wu, I.P. and H.M. Gitlin, 1982, Drip irrigation lateral line network design. Trans. of ASAE, 25(3): 675685. 